Revue des patrimoines

$41 \mid 2019$

Patrimoines gastronomiques. Définitions, typologies et enjeux de conservation

\title{
Patrimoines gastronomiques. Définitions, typologies et enjeux de conservation Éditorial
}

Marie-Hélène Bénetière, Isabelle Chave, Julie Faure et Michaël Vottero

\section{(2) OpenEdition \\ Journals}

Édition électronique

URL : http://journals.openedition.org/insitu/26436

DOI : 10.4000/insitu.26436

ISSN : $1630-7305$

Éditeur

Ministère de la Culture

Référence électronique

Marie-Hélène Bénetière, Isabelle Chave, Julie Faure et Michaël Vottero, « Patrimoines gastronomiques. Définitions, typologies et enjeux de conservation », In Situ [En ligne], 41 | 2019, mis en ligne le 15 décembre 2019, consulté le 24 septembre 2020. URL : http://journals.openedition.org/insitu/26436 ; DOI : https://doi.org/10.4000/insitu.26436

Ce document a été généré automatiquement le 24 septembre 2020.

\section{(c) $(1)$}

In Situ Revues des patrimoines est mis à disposition selon les termes de la licence Creative Commons Attribution - Pas d'Utilisation Commerciale - Pas de Modification 4.0 International. 


\title{
Patrimoines gastronomiques. Définitions, typologies et enjeux de conservation
}

\author{
Éditorial
}

Marie-Hélène Bénetière, Isabelle Chave, Julie Faure et Michaël Vottero

1 Depuis l'inscription, en novembre 2010, du repas gastronomique des Français sur la Liste représentative du Patrimoine culturel immatériel de l'humanité, l'intérêt et les questionnements autour de la gastronomie, envisagée comme fait patrimonial, n'ont cessé de croître. Cette reconnaissance internationale a de fait affirmé, avec une force incontestablement inédite, la dimension sociale, culturelle et patrimoniale de l'alimentation. Les aspects culturels et éducatifs du patrimoine gastronomique européen ont même fait l'objet d'une résolution du Parlement européen, le 12 mars 2014, sur le fondement d'un texte préparé par sa commission Culture, s'appuyant sur la double inscription de la diète méditerranéenne et du repas gastronomique des Français, par l'Unesco, en 2010 et $2013^{1}$.

2 La stimulation des travaux de recherche et le renouvellement des approches disciplinaires résultent aussi d'un surcroît de visibilité dû à cette distinction. Dans ce numéro, les témoignages de Pierre Sanner et de Solenne Livolsi présentent ainsi la mesure-phare du « plan de sauvegarde » de l'élément culturel reconnu par l'Unesco : ce réseau des Cités de la gastronomie, créé en 2013, à travers notamment la Cité internationale de la gastronomie de Lyon, inaugurée en ce mois de décembre 2019 au sein du Grand Hôtel-Dieu. La transmission des pratiques et des savoir-faire associés, au cœur des enjeux de la candidature en 2009-2010, y est exposée par un cas de sensibilisation par la création artistique (Julie Deramond et Laure Marchis-Mouren) et d'étude des filières de l'éducation formelle à l'étranger (Chia-Liang Hsu).

3 Proposer un état de la recherche et donner à voir ce patrimoine spécifique aussi en termes de préservation, de conservation et de valorisation culturelle et scientifique, tels sont les principaux objectifs de ce dossier thématique «Patrimoines gastronomiques: définitions, typologies et enjeux de conservation», élaboré au 
moment où s'ouvre l'année du dixième anniversaire de cette reconnaissance par l'organisation internationale.

4 Notons du reste que ce phénomène de mondialisation de la question gastronomique ne relève pas seulement de la place insigne, et à certains égards pionnière, faite à cet élément culturel sous la bannière du Patrimoine culturel immatériel. La simple évocation de l'accord entre les mets et les vins, au cœur de la tradition gastronomique française, donne aussi l'occasion de rappeler le rôle joué, dans ce changement d'échelle, par la convention de 1972 sur le patrimoine mondial, culturel et naturel. Dans l'inscription des "Coteaux, maisons et caves de Champagne» (2015) au Patrimoine mondial ont été pris en compte le bassin d'approvisionnement (coteaux historiques), les unités de production (caves souterraines) et les espaces de commercialisation (maisons de champagne), qui reflètent en effet, dans son ensemble, le processus de production de champagne ${ }^{2}$. De même, en visant la préservation et la transmission du patrimoine culturel et naturel de la Côte viticole bourguignonne, l'inscription des "Climats du vignoble de Bourgogne» (2015) a englobé, outre le site culturel et le patrimoine bâti lié à la culture de la vigne, un modèle spécifique de viticulture de terroir ${ }^{3}$. L'article proposé par Sophie Loppinet-Meo sur la chambre de commerce de Beaune y fait écho.

5 Au plan international comme à l'échelle nationale, les contours du patrimoine gastronomique apparaissent difficiles à cerner, d'où l'usage fréquent, et retenu pour le présent dossier, de l'expression au pluriel. À la fois matériel, immatériel, mémoriel, ... aux confins de champs de recherche aussi divers que l'alimentation, la botanique, l'architecture, les arts décoratifs, la sociabilité..., ce patrimoine, "protéiforme » et « incertain », pour citer l'article de Julia Csergo, convoquant de nombreuses disciplines scientifiques, semble avoir pour essence de se démultiplier à mesure qu'on le questionne.

6 Bon nombre d'éléments patrimoniaux concernés, sans pour autant être réunis sous l'intitulé clairement énoncé de " patrimoines gastronomiques ", sont aussi regardés et étudiés de longue date par des chercheurs de toutes disciplines, à commencer par les historiens et anthropologues de l'alimentation et les chercheurs en sciences du patrimoine en général.

7 La dimension sociale et culturelle de l'alimentation et ses fonctions dans la définition des identités individuelles et sociales, les classifications alimentaires et les mutations liées aux effets de la mondialisation sont investies très tôt par l'anthropologie, comme en témoignent les travaux en anthropologie de l'alimentation de Bronislaw Malinowski, Audrey Richards, Marcel Mauss ou Claude Lévi-Strauss ${ }^{4}$, les recherches de Jack Goody, Arjun Appadurai et Claude Fischler sur les mutations alimentaires et leurs conséquences sur la redéfinition des cadres culturels et des relations sociales, les articles publiés par la revue Terrain dans les années $1980-1990^{5}$ ou encore les rapports de recherche livrés à la mission Ethnologie du ministère de la Culture.

8 Depuis les années 2000, ces approches ont été relancées par des unités de recherche nouvelles ${ }^{6}$, sans compter les activités scientifiques conduites par l'Institut européen d'histoire et des cultures de l'alimentation (IEHCA) ${ }^{7}$, créé à Tours en 2001 et enrichi, l'année suivante, d'une bibliothèque de recherche spécialisée couvrant peu à peu tous les domaines des SHS. Dans leurs dimensions sociale, affective, économique et imaginaire, les cultures de l'alimentation se sont, au gré de leur internationalisation sensible, très nettement ouvertes à d'autres disciplines : histoire, sociologie, histoire 
des idées, des sensibilités et des représentations ${ }^{8}$, géographie, sciences du tourisme, écologie, économie, sciences politiques, droit ${ }^{9}$, sciences de l'information...

Quoique plébiscités, aussi bien des experts que du grand public, les patrimoines gastronomiques apparaissent à bien des égards menacés. Uniformisation des productions et du goût, consommation de masse, monopoles industriels, pertes des savoir-faire artisanaux, absence de transmission des gestes et des techniques, normes réglementaires trop rigides, disparition des temps et des lieux de ces prises alimentaires festives, évolution des usages et des manières de table, typologies architecturales parfois peu regardées, éléments de mobilier méconnus ..., bien des pans de ce patrimoine sont dénaturés ou disparaissent. Comment se compose et se recompose ce champ patrimonial, sous ses différents aspects, matériels et immatériels, afin d'envisager sa préservation sans pour autant le figer? Cette réflexion nourrit comme perspective d'étudier le renouvellement du regard des professionnels $d u$ patrimoine et des chercheurs sur cette thématique et l'accélération des collaborations interdisciplinaires.

10 Dans leurs spécialités respectives, bien avant l'inscription du repas gastronomique des Français par l'Unesco, les acteurs du patrimoine ont défriché le champ des pratiques culinaires. Ainsi, les études conduites selon la méthodologie des services de l'Inventaire général du patrimoine culturel (voir l'article de Julie Faure pour l'île-de-France), les chantiers de restauration ou de réhabilitation, les protections au titre des monuments historiques (voir l'article de Michaël Vottero pour la Bourgogne), la collecte de fonds spécialisés par les archives et les bibliothèques et la constitution de collections d'objets par les musées ont été, à eux tous, décisifs pour identifier, préserver, valoriser et sensibiliser ce patrimoine, tantôt bâti (voir les articles de Cécile Oulhen et Yann Celton sur la conserverie Le Gall de Loctudy, ou de Cécile Lestienne sur l'apparition de la salle à manger), tantôt mobilier, tantôt écrit (voir les articles de Sophie Bertrand, Alina Cantau et Dominique Wibault sur les périodiques culinaires de la Bibliothèque nationale de France, et de Guillaume Nicoud sur la première Carte gastronomique de la France).

11 Les produits culinaires de haute qualité (produits locaux, rares, du terroir, artisanaux ou emblématiques de la gastronomie) ont fait l'objet de constructions et de reconnaissances patrimoniales, au travers des matières premières, des techniques, des lieux de production, des usages, des représentations et des imaginaires associés, comme le montre bien l'essai d'analyse des légendes culinaires proposé par Loïc Bienassis.

Terrain de recherche de Claire Delfosse aujourd'hui, ces phénomènes de revitalisation, de relance de produits, de labellisations spécialisées (AOC, AOP, Label Rouge, IGP...) ${ }^{10}$ et de collectes documentaires font suite aux travaux conduits au cours des années 1970-1990, en particulier ceux soutenus par la mission Ethnologie du ministère de la Culture, à l'instar des quinze études en sociologie, éco-anthropologie et ethnobiologie rassemblées par Michel Rautenberg, Philippe Marchenay, Laurence Bérard et André Micoud, dans l'ouvrage Campagnes de tous nos désirs (2000) ${ }^{11}$, autour du renouveau de l'attrait pour la campagne (produits locaux, fêtes de la transhumance, engouement pour les parcs naturels régionaux).

13 La patrimonialisation est l'un des effets de la prise de conscience de la nécessaire préservation du patrimoine naturel, de l'intérêt des amateurs et des professionnels pour les variétés locales et plus largement, de la redécouverte, voire de l'invention, de produits « authentiques » ou « anciens $»^{12}$. Si l'article proposé par Marion Rouet sur les cultures de pointe pratiquées dans les potagers royaux en Île-de-France au XvIII ${ }^{\mathrm{e}}$ siècle 
fait constater l'ancienneté de cette sensibilité, le numéro propose plusieurs regards et témoignages sur les recherches qui se proposent aujourd'hui de faire renaître ce patrimoine végétal plus ou moins ancien (Yves-Marie Allain, Gilles Debarle et Audrey Didier).

Cette préservation patrimoniale des produits s'accompagne d'un processus équivalent pour leurs techniques de production et pour les savoir-faire qu'elles impliquent, comme le démontrent, dans des contextes géographiques et économiques radicalement différents, les articles de Christiane Dunoyer (Tarentaise) et d'Esther Katz et Lucia Hussak van Velthem (Amazonie brésilienne). La mise en patrimoine à l'œuvre s'enrichit d'une dimension forte de transmission, portée par divers acteurs et institutions (titulaires du diplôme "Un des meilleurs ouvriers de France ", confréries, guildes, foires, festivals...), de création plus ou moins récente. La culture des produits agricoles et les savoir-faire associés façonnent les territoires.

Les terroirs présentent des physionomies propres qui deviennent bien souvent identitaires, ainsi que l'étudie ici Delphine Cano pour le département de l'Ain, et peuvent faire l'objet de protections ou reconnaissances spécifiques, à l'échelle nationale, européenne ou internationale, avec leurs processus et leurs instances propres: coteaux de vignobles classés, alpages préservés, itinéraires culturels labellisés, les paysages de qualité ainsi constitués sont désormais entrés dans le champ patrimonial.

La traduction de ce mouvement sous forme de musées des produits du terroir, comme l'expose Florence Disson pour le secteur du cognac et du vin en Nouvelle-Aquitaine, est sans doute l'un des phénomènes les plus marquants du dernier tiers $d u x^{e}$ siècle. Après la création, en 1966, du musée de l'Art culinaire dans la maison natale du chef Auguste Escoffier, à Villeneuve-Loubet (Alpes-Maritimes), les années 1980 virent se multiplier musées de société et écomusées, publics ou privés, consacrés en tout ou partie aux traditions culinaires des terroirs ${ }^{13}$, tel le musée de la Gastronomie (1989-2000), au château de Grignon (Thiverval-Grignon, Yvelines) (fig. 1). 
Figure 1

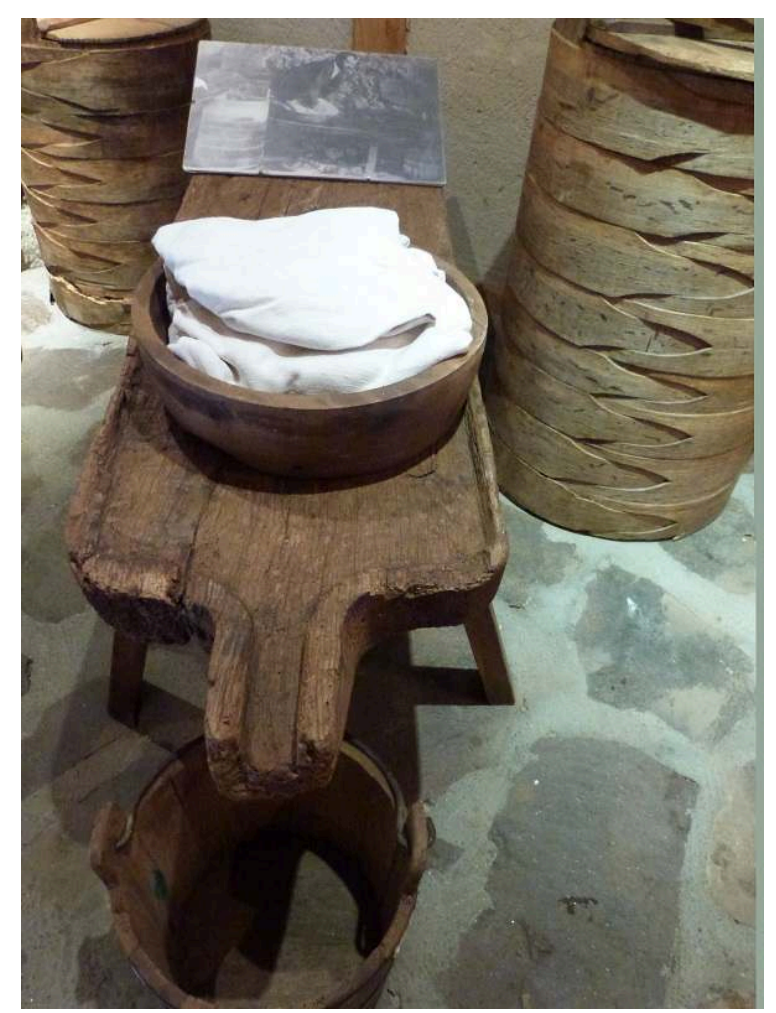

Écomusée des Burons de Salers, surplombant le volcan du Puy Mary et la vallée de la Maronne espace de présentation des outils des buronniers, 13 avril 2016.

Phot. Catherine Virassamy. (c) Greenandcraft, le comptoir des savoir-faire / Fédération des Sites remarquables du Goût, 2016.

17 La prise alimentaire, enfin, comme l'avait développé le dossier de candidature du repas gastronomique des Français autour des pratiques festives et sociales, porte sur la reconnaissance de l'art et des manières de table. Reflet des productions des créateurs d'arts décoratifs et de manufactures et entreprises françaises de renom, comme l'évoque le témoignage de Jeannine Guénot et de Denis Saillard sur les productions de la faïencerie de Lunéville, les arts de la table sont largement représentés au sein des collections nationales - sans recensement exhaustif connu, pour autant. Les objets conservés permettent aussi, comme l'a fait ici Jean-Michel Garric sur le pot à jus ou pot à crème, d'étudier la rapide évolution des usages et des ustensiles à l'appui. Redécouverts à l'occasion d'expositions marquantes, telles qu'À table au XIXe siècle (musée d'Orsay, 2001) ou Petits bouleversements au centre de la table (musée des Arts décoratifs, 2008-2009), ces récipients et instruments pour le service, la consommation et la conservation des aliments et des boissons sont souvent mis en contexte par le réseau des musées et des monuments nationaux dans les parcours permanents ou lors de manifestations temporaires. Des parcours thématiques y sont consacrés, offrant un lien didactique vers le champ du patrimoine artistique et des représentations picturales, gravées ou photographiques.

18 Sous la plume de professionnels du patrimoine et de chercheurs académiques, les vingtcinq articles rassemblés, retenus à la suite de la diffusion d'un appel à contributions au début de l'année 2019, ont été répartis en trois parties thématiques («Processus de patrimonialisation », "Produits culinaires » et "Arts et manières de table »), 
complétées par un ensemble, plus transversal, de "Témoignages». L'ampleur thématique et disciplinaire du sujet ainsi structurée, ce dossier thématique veut questionner de multiples manières, pluridisciplinaires et complémentaires, la notion même de "patrimoines gastronomiques" et la façon dont ils sont, depuis près de cinquante ans maintenant, identifiés, constitués, étudiés, conservés, protégés, valorisés et transmis.

\section{NOTES}

1. - Voir le texte de la résolution en ligne: http://www.europarl.europa.eu/sides/getDoc.do? pubRef=-//EP//TEXT+TA+P7-TA-2014-0211+0+DOC+XML+VO//FR [consulté le 25/11/2019].

2. - Voir le site dédié : https://whc.unesco.org/fr/list/1465 [consulté le 25/11/2019].

3. - Voir le site dédié : https://www.climats-bourgogne.com/ [consulté le 25/11/2019].

4. - Pour une synthèse, lire GARINE, Igor de. Anthropologie de l'alimentation et pluridisciplinarité. Aix-en-Provence : Laboratoire d'écologie humaine et d'anthropologie, 1988.

5. - Lire notamment FROC, Jean. « Un conservatoire des techniques fromagères traditionnelles en Normandie ». Terrain, $\mathrm{n}^{\circ} 6$, mars 1986 ; VIALLES, Noëlle. «La viande ou la bête ». Terrain, $\mathrm{n}^{\circ} 10$, avril 1988; dossier thématique "Boire». Terrain, n ${ }^{\circ}$, octobre 1989 ; BÉRARD, Laurence et MARCHENAY, Philippe. "Lieux, temps et preuves. La construction sociale des produits de terroir », et BREGEON-POLI, Brigitte. « "Va pour treize !". La « tradition » des desserts de Noël en Provence ». Terrain, $\mathrm{n}^{\circ} 24$, mars 1995 ; OUEDRAOGO, Arouna P. « Assainir la société. Les enjeux du végétarisme ». Terrain, $\mathrm{n}^{\circ} 31$, septembre 1998; FAURE, Muriel. «Un produit agricole "affiné" en objet culturel. Le fromage beaufort dans les Alpes du Nord ». Terrain, $\mathrm{n}^{\circ} 33$, septembre 1998.

6. - Parmi d'autres, l'équipe "Ressources des terroirs. Cultures, usages, sociétés » (UMR CNRS/ MNHN Éco-anthropologie et Ethnobiologie), l'UMR CNRS Mondes et dynamiques des sociétés (Modys) ou encore l'UMR 208 PALOC (IRD-MHN), qui a soutenu les projets «Foodherit Patrimoines alimentaires et gastropolitique : une approche critique et comparée (2013-2017)», dirigé par Charles-Édouard de Duremain, et «PALIM. Patrimoines alimentaires et pratiques culinaires (2015) ", dirigé par Esther Katz.

7. - Citons ainsi l'un de ses derniers colloques internationaux: «L'alimentation comme patrimoine culturel : enjeux, processus et perspectives » (15-16 novembre 2018).

8. - Voir par exemple les travaux de Jean-François REVEL (Un festin en paroles. Histoire littéraire de la sensibilité gastronomique. Paris : Pauvert, 1982), de Pascal ORY (Le Discours gastronomique français des origines à nos jours. Paris: Gallimard, 1998) ou de de Jean-Pierre POULAIN (Sociologies de l'alimentation : les mangeurs et l'espace social alimentaire. Paris : PUF, 2005).

9. - On peut évoquer le master de droit européen de l'Agriculture et des Filières agroalimentaires (université Paris 1) et l'Institut des sciences sociales du politique (ISP, ENS Paris-Saclay, université Paris-Nanterre, CNRS), qui s'est en particulier, à travers le programme de recherche "Osmose", soutenu par le ministère de la Culture depuis 2015, spécialisé dans le droit du patrimoine culturel immatériel.

10. - CHAVE, Isabelle. «Labels et procédés normatifs dans l'Inventaire français du PCI : un bilan 2017 ». Dans Labels et autres procédés normatifs du patrimoine culturel immatériel [actes de l'atelier international de recherche en droit comparé (programme « Osmose »). Paris, 10 novembre 2017], 
en ligne sur le blog Droit, patrimoine et culture : https://dpc.hypotheses.org/1890 [consulté le 25/11/2019].

11. - RAUTENBERG, Michel, MICOUD, André, MARCHENAY, Philippe et BÉRARD, Laurence. Campagnes de tous nos désirs : patrimoine et nouveaux usages. Paris : Éditions de la MSH, coll. « Ethnologie de la France », 2000.

12. - RAUTENBERG, Michel et TARDY, Cécile. «Patrimoines culturel et naturel : analyse des patrimonialisations ». Culture et Musées, hors-série "La muséologie, 20 ans de recherches", juin 2013, p. 115-138.

13. - Voir l'article «Les musées français à caractère culinaire", 3 septembre 2012, du blog Cookmyworld. Chroniques d'un gourmet voyageur ( http://www.cookmyworld.com/article-lesmusees-fran-ais-a-caractere-culinaire-109713721.html [consulté le 25/11/2019]).

\section{AUTEURS}

\section{MARIE-HÉLÈNE BÉNETIÈRE}

Chargée de mission Parcs et jardins, direction générale des Patrimoines, ministère de la Culture marie-helene.benetiere@culture.gouv.fr

\section{ISABELLE CHAVE}

Conservateur en chef du patrimoine, adjointe au chef du département du Pilotage de la recherche et de la Politique scientifique, direction générale des Patrimoines, ministère de la Culture isabelle.chave@culture.gouv.fr

\section{JULIE FAURE}

Conservateur en chef du patrimoine, service Patrimoine et Inventaires, Région Île-de-France julie.faure@iledefrance.fr

\section{MICHAËL VOTTERO}

Conservateur régional adjoint des Monuments historiques, direction régionale des Affaires culturelles Bourgogne-Franche-Comté michael.vottero@culture.gouv.fr 